Review - Smart Energy

\title{
State of the Art of the Application of Energy Storage Systems in Photovoltaic Buildings
}

\author{
Juliana D'Angela Mariano' \\ https://orcid.org/0000-0002-2740-2814 \\ Jair Urbanetz Junior ${ }^{1}$ \\ https://orcid.org/0000-0001-9355-1730
}

${ }^{1}$ Universidade Tecnológica Federal do Paraná,LABENS, PPGSE, UTFPR, Curitiba,Paraná, Brasil;

Received: 2018.11.05; Accepted: 2019.07.26.

* Correspondence: julianadangela@gmail.com; Tel.: +55-41-995087417 (J.D.);

urbanetz@utfpr.edu.br; Tel.: +55-41-33104626 (J.U.)

\section{HIGHLIGHTS}

- Energy storage technologies together with photovoltaic (PV) systems overview is presented.

- Energy storage modes are descripted.

- Energy storage applications in PV buildings are shown.

- A case of study is analyzed.

\begin{abstract}
Photovoltaic (PV) buildings are increasingly present in urban centers and can generate their own energy becoming independent of the grid, depending on their consumption profile. However, most residential and commercial consumers show their peak demand at night, when there is no photovoltaic generation, needing the electricity grid to meet the demand of these facilities. Peak demand lead to increased costs for these consumers and end up disrupting the power quality of the grid. One possible solution for these listed problems is by applying storage systems to these buildings, which is already being done in some countries and can increase the PV generation. Aiming to seek the state of the art of these systems, this article brings a review of the literature, highlighting the possible modes of operation and a real case of application in PV buildings in the world. Also are described the storage technologies most appropriate for applications in these buildings, highlighting their advantages and disadvantages. It is expected to gain greater knowledge of these systems, in order to overcome the challenges of intermittence generated by renewable sources, enabling the reduction of energy demand costs in these customers so that it can also be applied in the Brazilian scenario.
\end{abstract}

Keywords: Photovoltaic Buildings; Energy Storage; Peak Demand Reduction. 


\section{INTRODUCTION}

Energy storage technologies are considered as key elements for a sustainable future in energy supply through distributed generation [1]. In photovoltaic systems, where they typically operate at substantial penetration levels due to intermittent generation, there are some challenges to be overcome both in the cost difference at peak demand times, as well as the power quality that these systems deliver to the electric grid [2].

In this sense, energy storage systems generally operate with decentralized power systems, such as photovoltaic systems for power management, i.e. load leveling or peak demand reduction, for power bridges and power quality improvements [3]. Thus, energy storage is better, not only to reduce peak demand, but also to reduce customers' energy costs. The joint operation of these systems with demand-side response can efficiently reduce energy costs and decrease peak demand from the power grid [2].

The addition of photovoltaic and energy storage systems is attractive to the largest consumers of electricity, where the highest demand charges are incurred. For these systems to be viable it is necessary to promptly and accurately determine reductions in peak demand, as demand rates constitute the greater part of commercial electricity bills and, in some cases, may be greater than $40 \%$ of the utility electric power bill [4].

On the other hand, countries such as Germany, the use of these systems in small-scale residential consumers has been a reality in recent years. This is due to rising electricity prices and falling prices of these systems, where even with the many critical aspects inherent in their implementation, they are still attractive for residential applications [1].

Energy storage systems consist of the use of batteries and inverter / charger coupled with distributed generation promoting several benefits for these systems and can operate in various functions, which will be described in this literature review.

\section{MATERIAL AND METHODS}

Energy storage integrated with renewable energies is still little used in Brazil, being restricted to research and development institutions. In 2018, several studies were published seeking to disseminate experiences and results of applications of these systems together with photovoltaic buildings. The methodology used in the research was state of the art on the proposed theme, through bibliometric analysis on Scopus, ScienceDirect bibliographic platforms, collections of theses and dissertations from universities, among others.

Regarding the selection criteria, the following aspects were taken into consideration: (i) article titles aligned with the research theme; (ii) abstracts aligned with the research theme; (iii) result relevance filter; and (iv) full text of articles aligned with the research theme. There is no temporary limitation of publications [5]. The analysis resulted from the information obtained resulting from the elaboration of the article, highlighting the functionalities, mode of operation, benefits, types of technologies and real applications of storage systems, as well as the challenges to be overcome by the sector.

\section{ENERGY STORAGE AND MODES OF OPERATION}

Akhil et al. (2013) [6] describe the 18 possible modes of operation for energy storage functionalities and their simultaneous uses within 5 categories: ancillary services, transmission services, distribution services, bulk energy system and consumer energy management. When talking about photovoltaic buildings, it is possible to apply these last 2 categories mentioned above contemplating 6 modes of operation which will be described below.

For bulk energy there are 2 modes of operation: time-shifting and electric supply capacity. In load shifting operation mode, energy is purchased during periods when prices are lower and can be stored in these systems for use or sale at times when energy prices are high. This mode of operation combined with PV generation can also store the surplus energy produced to be used when there is a higher demand for energy [6]. 
Already in power supply mode, also known as peak-shaving is a form of operation that enables the reduction of peak demand through storage to meet a certain load or reducing the need to buy new energy demand. With this mode of operation, the PV system will be able to discharge its energy through the batteries for a period, such as during rush hour.

Regarding consumer power management services, there are 4 modes of operations [6]: power quality, back-up, high-end power selling and demand-side load management. Operations in power quality mode involve the application of storage to protect customer loads against events that may affect their loads, such as:

- Voltage variations (for example, peaks or short-term declines, long-term peaks or declines).

- Variations in the primary frequency of $60 \mathrm{Hertz}(\mathrm{Hz})$ at which power is supplied.

- Low power factor (excessively out of phase voltage and current).

- Harmonics (i.e. the presence of currents or voltages at frequencies other than the primary frequency).

- Service interruptions of any duration, ranging from a fraction of a second to several seconds.

In energy backup mode, a storage system is capable of effectively supporting customer loads when there is a total loss of power. The storage system's power capacity relative to the size of the load it is protecting determines how long the storage can meet that load and be resynchronized, a feature available as demand reduction [6].

In order to reduce electricity costs, it is possible for end users to use storage for the sale of power at the peak. This mode of operation consists of applying storage when the customer charges for this service during off-peak periods and then offloads energy during periods when energy prices are highest. This application is like the electricity travel time, although electricity prices are based on the customer's retail tariff, while at any time the price of electricity travel is the wholesale price [6].

Finally, it is also possible for consumers to manage their load according to demand in order to reduce electricity costs at the peak demand specified by the utility. Akhil et al. (2013) [6] point out that in order to avoid demand charging, the load must be reduced during all hours of the demand collection period, usually a specified period (for example, from 19:00 to 21:00) and on specified days (more often on weekdays).

Energy storage can be applied to any of the services mentioned above, as it is not common for the use of only one service to result in an attractive return on investment, that is why it is possible simultaneous uses [6]. However, the simultaneous use of these listed services depends on the type of technology employed and the location of the system within the network, as there are regulatory and operational restrictions. Therefore, these combined applications require careful planning and should be analyzed on a case-by-case basis, especially regarding the chosen inverter.

\section{POWER STORAGE APPLICATIONS IN PV BUILDINGS}

Del Pero et al. (2018) [7] state that energy can be stored and retrieved later, at a different location and perhaps at different temperature levels, to bridge the gap between energy supply and demand. This is possible based on the thermodynamic laws of energy transformations between different forms of energy. In this sense, there are 4 types of technologies available for energy storage application: magnetic, mechanical, chemical and thermal, as shown in Figure 1. 


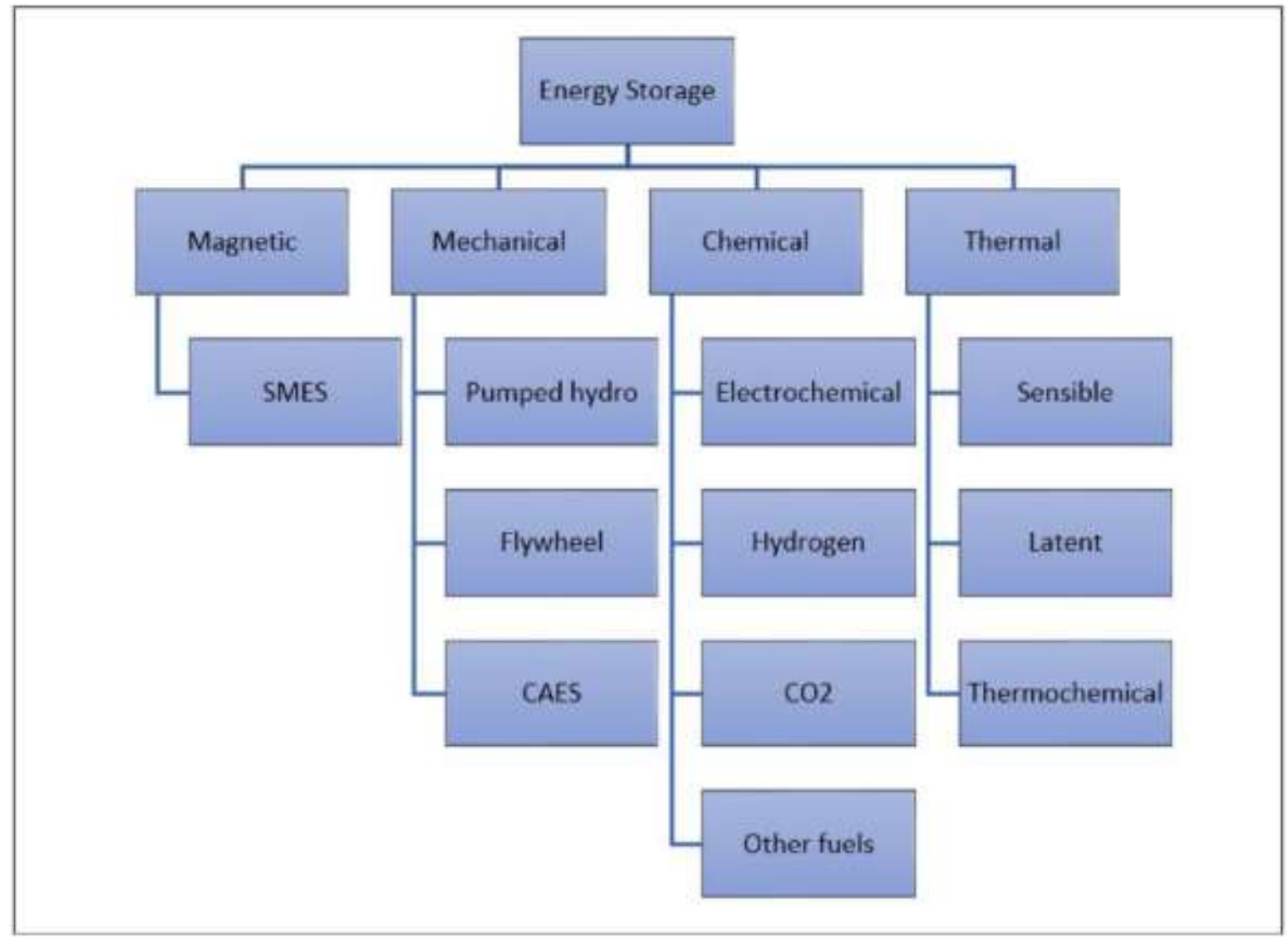

Figure 1. Storage Technologies Classification [7].

Among these various topologies, the most suitable applications for buildings are described below (* SMES: Supermagnetic Energy Storage; * CAES: Compressed Air Energy Storage) [7]:

- Short-term passive storage: consists of using building components for thermal energy storage in the form of sensitive or latent heat storage;

- Short-term active storage: consists of applying water tanks with or without phase change materials (latent / thermal sensitive), ice storage (thermal latent), batteries (electrochemical), flywheels (mechanical), supercapacitors (electrochemical), energy storage of compressed air and hydrogen (chemical);

- Active seasonal storage: typically, using underground thermal (heat sensitive) or thermochemical storage.

Energy storage in buildings is generally intended for power supply, heating, hot water cooling. The following are the 3 most common energy storage applications in buildings.

So that the building can perform the services of: load shifting (time-shifting); electric supply capacity; Power quality, reliability (back-up), high-end power sales and on-demand load management require the application of chemical and mechanical storage technologies. However, active storage through flywheels and supercapacitors (mechanical) has very limited energy penetration for these services, and the most appropriate electrochemical technology.

According to Del Pero et al., (2018) [7] there are several parameters that should be considered depending on the application, namely: energy, discharge depth, cost, safety, conditions guaranteed by the manufacturer, ambient temperature, maintenance, as well as availability of space required for installation in the building. For this type of application, there are a variety of technologies available on the market, with technical parameters and capacity in the following types: 
- Lead acid batteries: These are the oldest and most widely used rechargeable electrochemical devices, where lead and lead oxide electrodes are used in an electrolyte containing about $37 \%$ sulfuric acid [8].

- Flow batteries: These are batteries where energy is stored directly in the electrolyte solution for extended life cycles and fast response times [8].

- Lithium-ion batteries: consists of a cell containing two reactive materials capable of undergoing a chemical electron transfer reaction [6].

Akbari et al. (2018) [8] claim that lead acid batteries were invented in 1859 and remain a popular storage option for power quality, uninterceptable power supply (UPS) and some power applications such as revolving reserve. Due to its short life cycle limitation and low energy density, the application for power management is severely compromised. In this sense, a thermal parameter management system is required to overcome the low temperature low performance of this technology.

In contrast to conventional batteries, flow batteries store energy in electrolyte solutions. Power and energy ratings are independent of the storage capacity determined by the amount of electrolyte used and the power rating by the active cell area of the cells. Flow batteries can continuously release energy at a high discharge rate for up to 10 hours [8].

Already in lithium-ion batteries its efficiency is almost $100 \%$ compared to other technologies. This technology is present in the $50 \%$ market of small portable devices, and its biggest challenge is the large-scale production due to the high cost (>600/kWh), because they need special packaging and internal overload protection circuits. However, its high reactivity with air and humidity can cause fire, which poses a high safety risk [8].

Del Pero et al., (2018) [7] further highlight the existence of other emerging storage technologies, such as hydrogen and compressed air, where some companies are already supplying in their portfolio, but that their viability is not yet feasible application due to low efficiency, technical limitation, high investments and very limited application in buildings.

\section{Case Study of a Power Storage Residential PV System}

In the Brazilian scenario, there are few applications of photovoltaic systems that contemplate electrochemical storage being restricted to the university and research centers. For this reason, a case study of the SoLa Bristol project (Buildings, Renewables and Integrated Storage, with Tariffs to Overcome Network Limitations), located in England, will be presented below. The initiative originated through the Western Power Distribution electricity company, which comprised 26 homes and 6 office buildings, including 5 schools and 1 office in the city of Bristol. This project had 2 phases, the first being the photovoltaic modules installation on the roofs of these customers, while the second phase included the installation of batteries to meet the charges, as shown in Figure 2 [2] [9] [10].
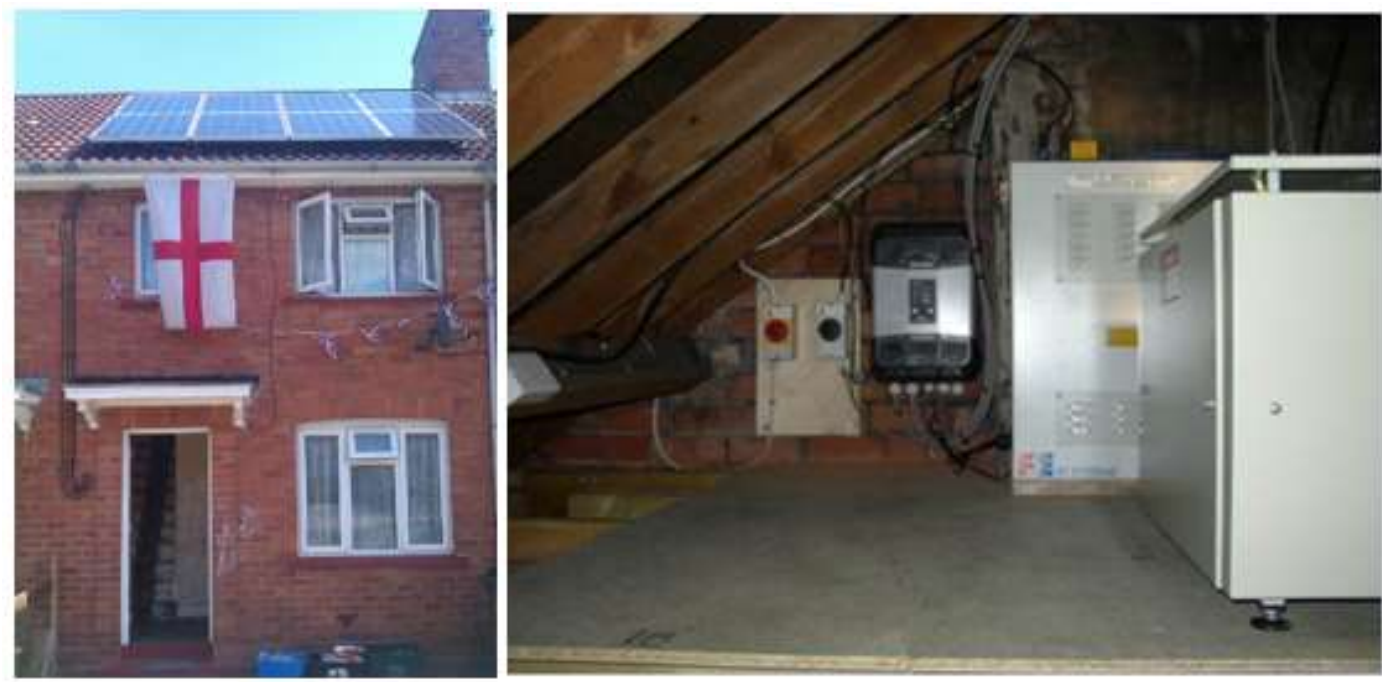

Figure 2. Photovoltaic system with storage [9] [10]. 
Some graphs are presented below to demonstrate the modes of operation and results achieved with the implementation of this set. These systems operate in the following modes: Peak Shaving Reduction; Load shifting; Voltage level regulation using lead acid (4.8 kWh) batteries and $3.5 \mathrm{kWp}$ installed photovoltaic power. Figure 3 shows the differentiation of charging and discharging periods performed by the battery bank.

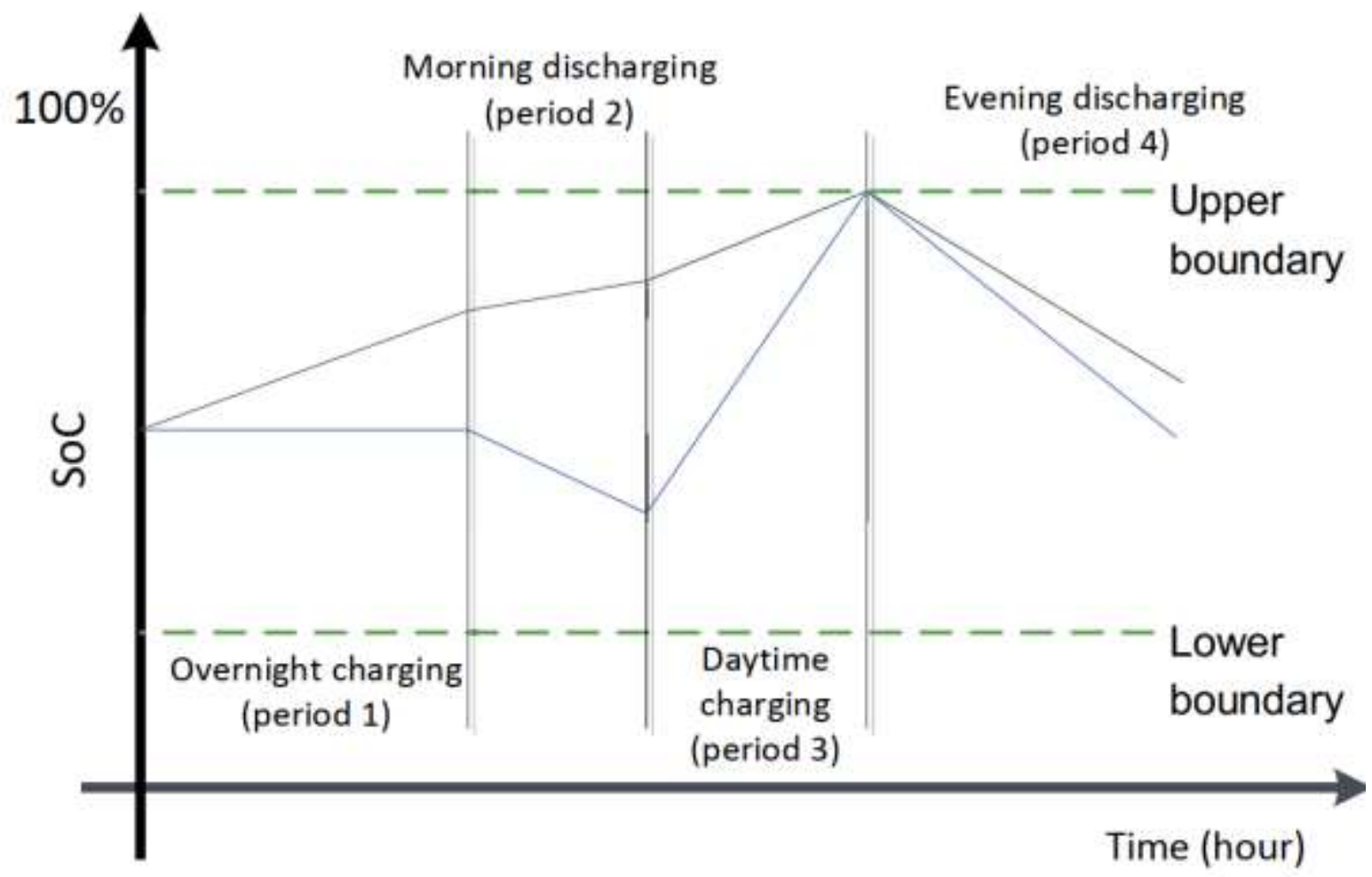

Figure 3. Differentiation between battery charging and discharging periods [2].

According to photovoltaic system output and load profiles there are approximately four periods, where in Period 3, due to the energy being produced mainly during the day, storage loading is encouraged. In Period 4, due to low photovoltaic output and peak demand occurring during this period, storage is discharged [2]. Figure 4 shows the profiles on a typical winter day. 


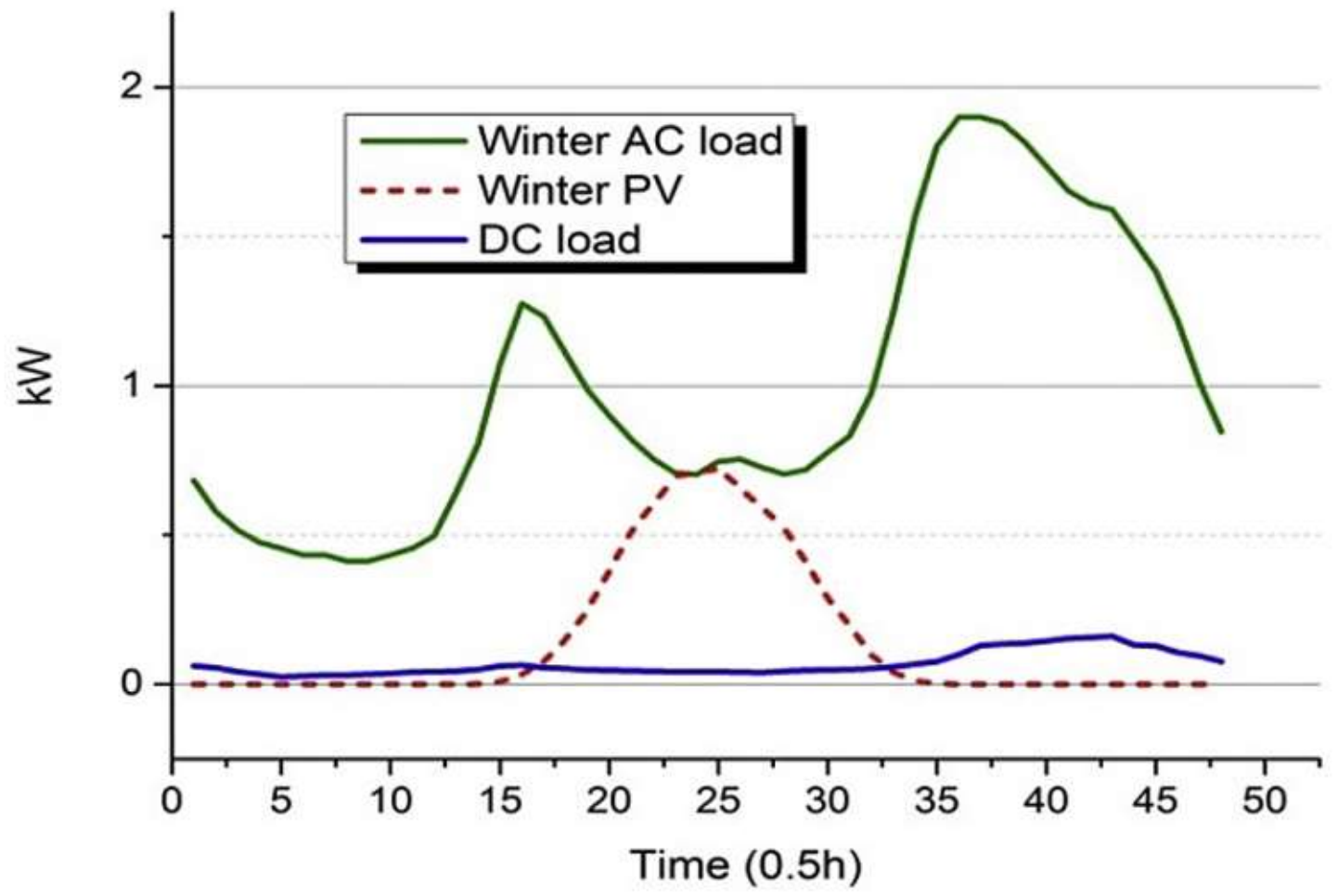

Figure 4. Load profiles and photovoltaic generation in winter [2].

Wang et al. (2018) [2] affirm that usually the demand for AC (alternating current) load in winter is higher than in other seasons, with an early evening peak near $2 \mathrm{~kW}$. Charging strategies for battery storage at different stations are designed based on typical PV system load and output profiles. In Figure 5 Wang et al., (2018) [2] bring a graph that demonstrates the load profile in these customers, analyzing typical winter days with network overload.

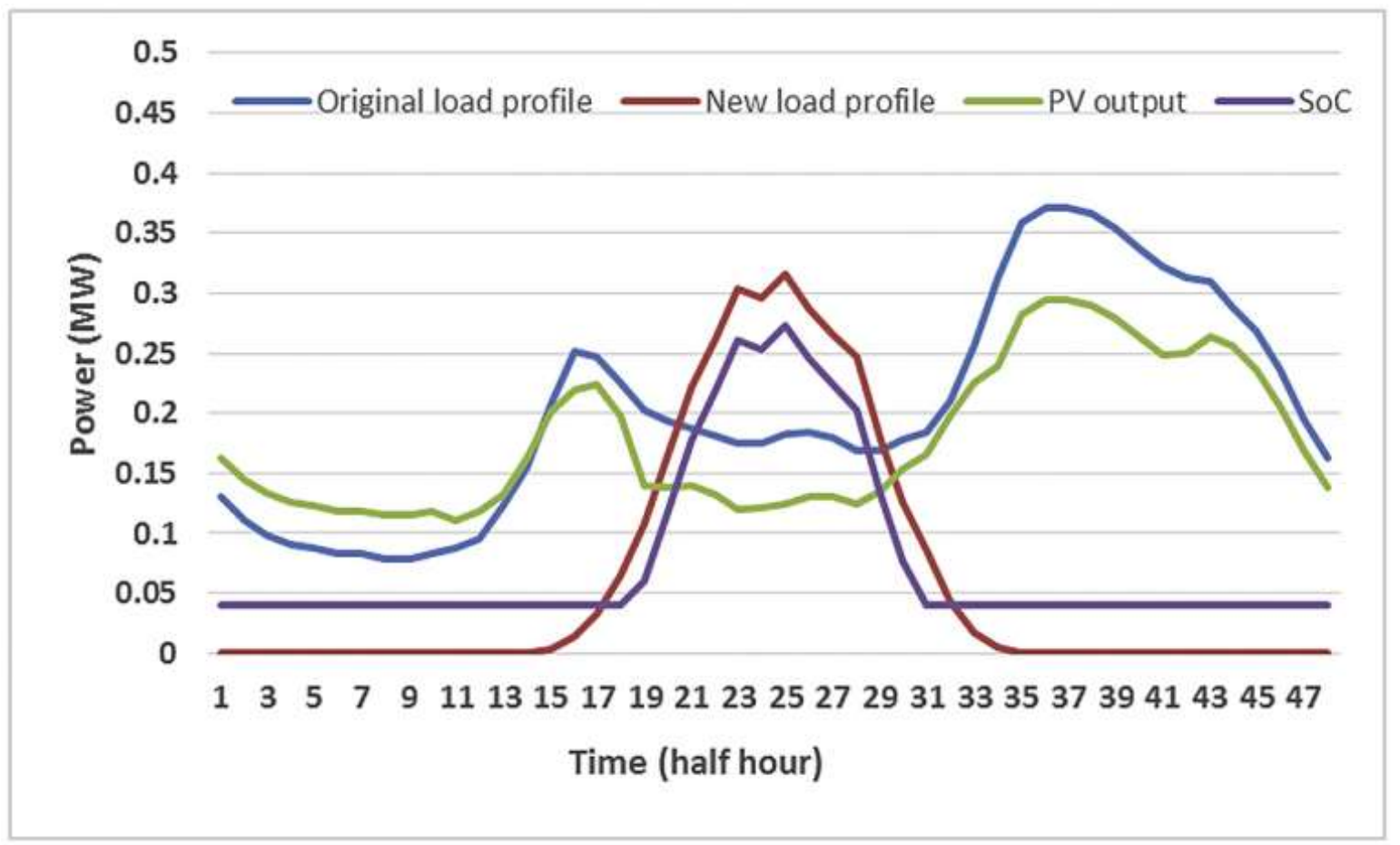

Figure 5. New winter profile [2]. 
According to Figure 5, the new load curve shows a $0.082 \mathrm{MW}$ reduction in peak demand with the application of energy storage. The daytime demand is significantly reduced due to photovoltaic generation, which usually occurs at times of lower energy demand in a home.

Making a projection to the Brazilian scenario, the joint application of energy storage systems with PV systems in buildings could have a better use in charging the batteries using the PV system. This assumption could be applied in commercial buildings, where their energy demand profile is generally daytime, besides having greater availability for application of these systems.

In this sense, from this study, we propose further analysis of the application of different storage technologies compatible with the Brazilian scenario, so that there is greater energy penetration generated by PV systems, which are increasingly expanding in Brazil.

\section{CONCLUSION}

This review article has brought out the various energy storage options for photovoltaic energy, including electric energy storage systems. Energy storage in PV buildings describes the role of storage for the solution of PV generation intermittence in the context of future application options of these systems, especially in the Brazilian scenario, where there is an abundance of solar resources and expansion of the application of PV systems.

Therefore, each technology has its pros and cons, in the case of lead acid batteries have reduced cost, but reduced cycle numbers and energy density in return. Flow batteries offer intermediate cycle numbers and costs, but low energy density, which requires larger spaces for their application. On the other hand, lithium ion batteries require higher investment, but have higher energy density and number of cycles. Therefore, each application requires thorough analysis of electrical, chemical and environmental parameters, as well as the cost of technologies for the intended storage objectives.

Funding: This research was funded by COPEL-DIS, grant number 2866-0464/2017.

Acknowledgments: The authors acknowledge the Federal University of Technology - Paraná for the infrastructure available to develop this research.

Conflicts of Interest: The authors declare no conflict of interest. The funders had no role in the design of the study; in the collection, analyses, or interpretation of data; in the writing of the manuscript, or in the decision to publish the results.

\section{REFERENCES}

1. Munzke, N.; Scharwz; B.; Barry, J. The impact of control strategies on the performance and profitability of Ii-ion home storage system. In 11th International Renewable Energy Storage Conference, IRES 2017, Energy Procedia, Düsseldorf, Germany, 14-16 March, 2017, n. 135, p. 472-481.

2. Wang, Z.; Gu, C.; Li F. Flexible operation of shared energy storage at households to facilitate PV penetration, Renewable Energy 2018, v. 116, pp. 438-446.

3. Opiyo, N. Energy storage systems for PV-based communal grids, Journal of Energy Storage 2016, v. 7, pp. 1-12.

4. Park, A.; Lappas, P. Evaluating demand charge reduction for commercial-scale solar PV coupled with battery storage. Renewable Energy 2017, v. 108, pp.523-532.

5. Monteiro, N. DA S. C.; Monteiro R. A. B.; Mariano J. D. A.; Urbanetz Junior J.; Romano, C. A. Brazil Market Outlook for Photovoltaic Solar Energy: A Survey Study, British Journal of Applied Science \& Technology 2017, v. 33408, pp 1-11.

6. Akhil, A. A.; HUFF, G.; Currier, A. B.; Kaun B. C.; Rastler D. M.; Chen S. B.; Cotter, A. L.; Bradshaw, D. T.; Gauntlett, W. D. In DOE/EPRI 2013 Electricity Storage Handbook in Collaboration with NRECA, Sandia National Laboratories, $1^{\text {st }}$ ed.; Alburquerque, United States of America, 2013, v.1, pp 340.

7. Del Pero, C.; Aste, N.; Paksoy, H.; Haghighat, F.; Grillo, S.; Leonforte, F. Energy storage key performance indicators for building application, Sustainable Cities and Society 2018, v. 40, pp. 54-65. 
8. Akbari, H., Browne, M. C., Ortega, A., Huang, M. J., Hewitt, N. J., Norton, B., \& McCormack, S. J. Efficient energy storage technologies for photovoltaic systems, Solar Energy 2018, v1. pp. 125.

9. KWMC (Knowle West Media Centre). Available online: http://kwmc.org.uk/projects/solabristol/ (accessed on 24 March 2018).

10. Western Power. Available online: http://www.westernpower.co.uk/ (accessed on 24 March 2018).

(c) (7) \& 2018 by the authors. Submitted for possible open access publication BY NC BY NC) license (http://creativecommons.org/licenses/by-nc/4.0/). 